Jusmal lemiah
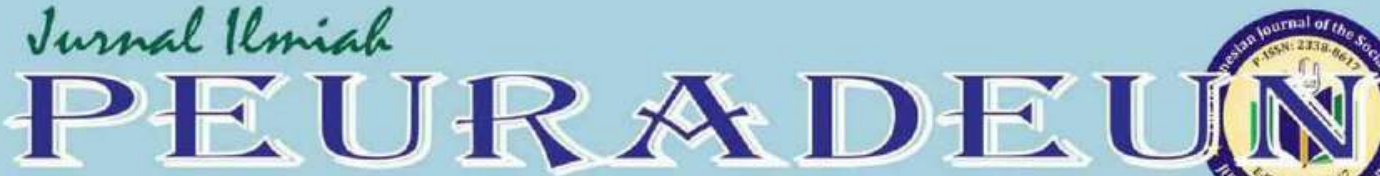

Vol. 6, No. 1, January 2018

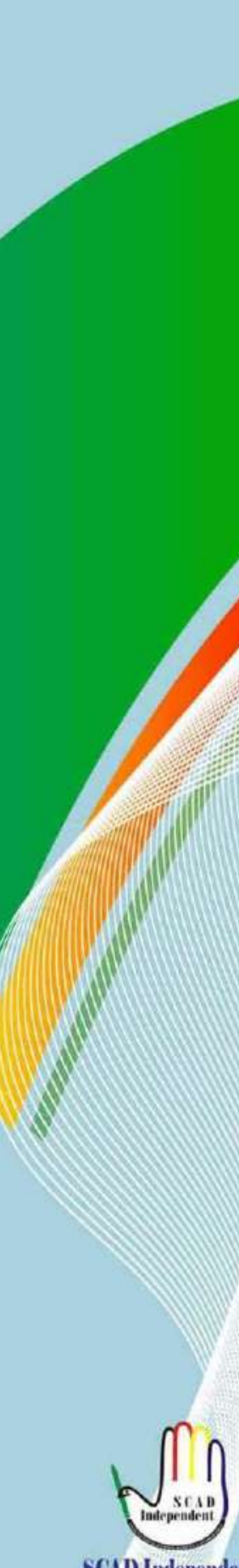

SCAI) Independent Accreditatioa by HO since 2014 $\bigodot$ Copernicus Publications

\section{III}

The Indonesian Journal of the Social Sciences www.journal.scadindependent.org Dot Prefix Number: 10.26811

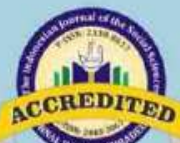

ACCREDITED - B" by the Ministry of Risteklikti from Oetaber 30, 2017 until Oetober 30, 2022

\section{Clarivate Analytics}

Emerging Sources Citation Index Web of Science ${ }^{\mathrm{TM}}$

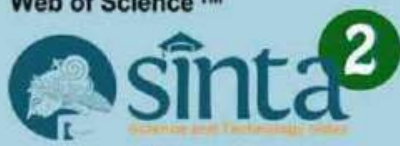
INDEX $\circledast$ COPERNICUS 


\title{
ASSESSING MEDIATING EFFECT OF MOTIVATION TYPES ON COMPETITION INTERVENTION FOR PHYSICALLY INACTIVE ADULTS
}

\author{
Fatmawati $^{1}$; Andrew Prestwich ${ }^{2}$; Bianca Sykes-Muskett ${ }^{3}$ \\ ${ }^{123}$ School of Psychology, the University of Leeds, United Kingdom \\ Email: ${ }^{1}$ ps14ff@leeds.ac.uk; 2a.j.prestwich@leeds.ac.uk;3b.j.sykes06@leeds.ac.uk
}

Received: July 07, 2017

Accepted: Oct 17, 2017

Published: Jan 28, 2018

Article Url: http://journal.scadindependent.org/index.php/jipeuradeun/article/view/156

\begin{abstract}
Competition has been widely used as the behaviour change technique for physical activity intervention, this approach might push someone motivation to achieve the desired behaviour. Therefore, the objective of this study was to assess the mediating effects of the motivation on the competition intervention effectiveness. An experimental research was conducted where participants were randomly allocated into one of two groups (control and competition group). For calculating the motivation types, Behavioural Regulation in Exercise Questionnaire (BREQ2) was administered. The results revealed that motivation was not found to mediate the effect of competition intervention.
\end{abstract}

Keywords: Competition Intervention, Physically Inactive, Motivation Types, Adults 


\section{A. Introduction}

Nowadays, competition has been widely used as the behaviour change technique for physical activity intervention (Peng, Crouse, \& Lin, 2012), this approach might push someone motivation to achieve the desired behaviour. According to Malhotra (2009), competitive environment can heighten someone motivation due to the desire to win. The research conducted by Foster, Linehan, Kirman, Lawson, and James (2010) also stated that the competitiveness stimulated by the motivational goal has the higher tendency to be successful, thus the use of game-based intervention is effective to improve walking behaviour as it assists people to establish the social competition atmosphere.

Self-determination theory (SDT) is one of the human motivation theories which uniquely explain about the different types of motivation (Ryan \& Deci, 2002). This theory is a comprehensive approach incorporating human perspectives, self-actualization, and personality (Fortier, Duda, Guerin, \& Teixeira, 2012), as well as the only theory of motivation that obviously identifies the autonomy as a human need (Milyavskaya \& Koestner, 2011; Mata et al., 2009). SDT gives the holistic understanding about physical activity through cognitive, affective, and motivational aspects (Teixeira et al., 2012; Silva et al., 2010). In SDT, motivation is presented in more detail definition consisting of three different classifications, namely (1) intrinsic motivation, (2) extrinsic motivation, and (3) amotivation (Deci \& Ryan, 2012).

Intrinsic motivation emphasizes the importance of internal pleasure as the trigger factor for doing something (Ryan \& Deci, 2002). In terms of physical activity, intrinsic motivation is determined by enjoyment and satisfaction, where people will be inherently motivated to do exercise without considering achieving any rewards (Lim \& Wang, 2009). Intrinsic motivation is driven by pure excitement which is the highest form of autonomous and leads into the maximum level of exercise motivation (Mata et al., 2009). Besides, this type of motivation also categorizes as the highest degree of self-determination (Ryan et al., 2009), and some studies found that the higher the level of self-determination, the more people 


\section{Fatmawati et al.}

engage with physical activity (Chatzisarantis \& Hagger, 2009; Brunet \& Sabiston, 2011; Rodgers, Hall, Duncan, Pearson, \& Milne, 2010).

In contrast with intrinsic motivation, extrinsic motivation highlights the role of outcomes as the rewards of doing something (Ryan \& Deci, 2002). According to Ryan et al. (2009), this motivation consists of 3 different regulation categories, namely (1) external, (2) introjected, and (3) identified. Moreover, extrinsic motivation also encompasses internalization and integration, where the internalization refers to the value or regulation assimilation, whereas the integration concerns to the adoption process of value into individual routine (Deci \& Ryan, 2002; Ryan et al., 2009; Chemolli \& Gagné, 2014). Below is the schema which shows the continuum of motivation in SDT.

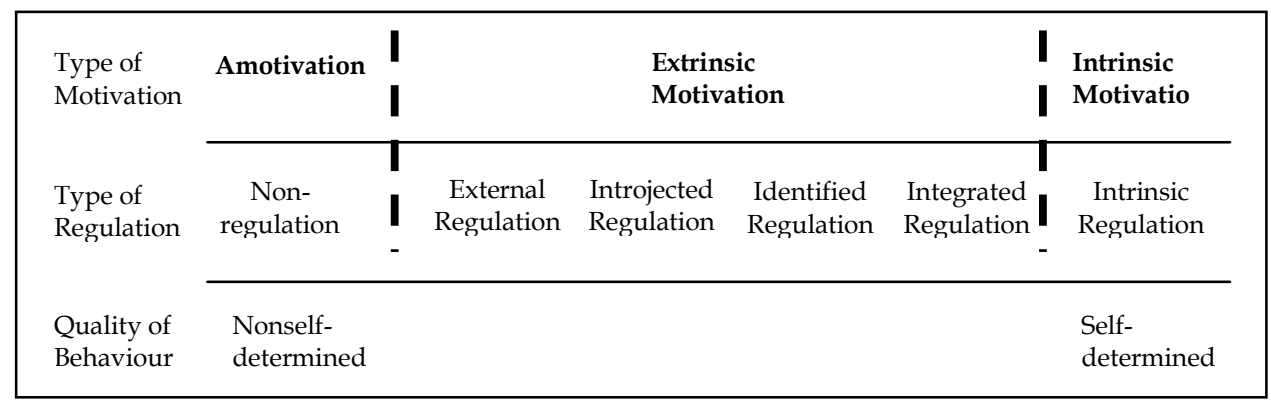

Figure 1. A continuum of self-determination ranging from completely non-self-determined to completely self-determine Source: Ryan and Deci (2002), p.16

As the macro theory of motivation, self-determination theory also provides the most essential distinction between autonomous motivation and controlled motivation (Deci \& Ryan, 2012). Autonomous motivation contains both intrinsic and several categories of extrinsic motivation, in which people have identified and integrated their sense of self with the value of activity (Deci \& Ryan, 2012). Some research findings stated that this motivation is more likely to yield better health outcomes and guide into greater long-term health behaviour maintenance (Rouse, Ntoumanis, Duda, Jolly, \& Williams, 2011; Ng et al., 2012).

Conversely, controlled motivation consists of external regulation, where people values the behaviour as rewards or punishments; and 
introjected regulation, where the value of behaviour has been partially internalized and empowered by several factors, such as avoidance of shame and ego-involvements (Deci \& Ryan, 2012). Both autonomous and controlled motivation may lead and energize the behaviour (Rouse et al., 2011), and they are dissimilar to amotivation which relates to low of intention and motivation (Deci \& Ryan, 2012).

Hence, it is clear that the mediating effects of motivation types need to be investigated in the further study, where the results can be used to design a more comprehensive intervention, especially in physical activity.

Based on the explanation above, to conclude, this study proposed two hypotheses, namely: Hypothesis 1 - The competition intervention group would significantly increase the scores of (a) external motivation, (b) introjected motivation, (c) identified motivation, (d) intrinsic motivation, and decrease the score of (e) amotivation relative to a control group. Hypothesis 2 - The effect of the competition intervention on pedometer steps would be mediated by change in (a) external motivation, (b) introjected motivation, (c) identified motivation, (d) intrinsic motivation, and (e) amotivation scores.

\section{B. Method}

This study was based on experimental design. The numbers of eligible participants recruited were 32. Those participants who met the criteria were assigned into one of two groups -competition and control group. Each participant within both groups was asked to achieve 10,000 steps a day and wear a pedometer (provided by researchers). However, only participants in competition group divided into two "league" groups where every participant competed against another in their league.

The length of the study was two weeks, in which baseline and intervention period was one week, respectively. Prior to baseline, named as Session 1, all participants invited to School of Psychology (SoP), University of Leeds, to provide consent and fill the paper-based questionnaires. Then, the participants were asked to return to SoP in two more occasions -Session 2, a week after Session 1, and Session 3, a week 
after Session 2 (two weeks after Session 1). In these sessions, they asked to complete numerous paper-based questionnaires.

In order to measure steps achieved, a pedometer was worn everyday within two weeks, and at the end of each day, a photo of pedometer reading must be sent to the researchers. For competition group only, a league table was sent to them during the intervention period in order to show their position compared to other participants in the league.

The mediating effect of motivation towards competition intervention was measured by using the second version of Behavioural Regulation in Exercise Questionnaire (BREQ-2) (Mullan, Markland, \& Ingledew, 1997; Markland \& Tobin, 2004) which consists of 19 questions. This measure has been previously found to be valid and reliable to investigate the motivation for physical activity among young adults, adults, and middle-age adults (Brunet \& Sabiston, 2011).

The BREQ-2 was administered during session 2 and 3. The answers from the participants were ranged from 0 (not true for me) to 4 (very true for me) and calculated based on 5 types of motivation, namely external regulation -assessed by 4 items (i.e. "I would do at least 10,000 steps per day over the next week because other people say I should"), introjected regulation -assessed by 3 items (i.e. "I would feel guilty if I don't do at least 10,000 steps per day over the next week)", identified regulation -assessed by 4 items (i.e. "I value the benefits of doing at least 10,000 steps per day over the next week)", intrinsic regulation -assessed by 4 items (i.e. "I would do at least 10,000 steps per day over the next week because it's fun)", and amotivation -assessed by 4 items (i.e. "I don't see why I should have to do at least 10,000 steps per day over the next week)".

For statistical analysis, an ANCOVA was performed to identify the effect of competition intervention on the change of motivation types during session 2 (pre- and post-manipulation) and session 3. If ANCOVA revealed any significant effects of the intervention on the motivation types, thus a Nonparametric Bootstrapping Analysis would be operated in 
order to investigate the mediating effects of the motivation types on the relationship between competition intervention and pedometer steps.

\section{Research Findings}

The mean scores of each motivation type from session 2 (pre- and postmanipulation) to session 3 between two groups were summarized in Table 1.

Table 1:

Means and Standard Deviations of Motivation Types at Session 2 (Pre- and Post-Manipulation) and Session 3 for Control and Competition Group

\begin{tabular}{|c|c|c|c|c|c|c|}
\hline \multirow{3}{*}{$\begin{array}{l}\text { Motivation } \\
\text { Types }\end{array}$} & \multicolumn{4}{|c|}{ Session 2} & \multirow{2}{*}{\multicolumn{2}{|c|}{ Session 3}} \\
\hline & \multicolumn{2}{|c|}{ Pre-Manipulation } & \multicolumn{2}{|c|}{ Post-Manipulation } & & \\
\hline & $\begin{array}{c}\text { Control } \\
\text { Mean } \\
\text { (SD) }\end{array}$ & $\begin{array}{c}\text { Competition } \\
\text { Mean } \\
\text { (SD) }\end{array}$ & $\begin{array}{c}\text { Control } \\
\text { Mean } \\
\text { (SD) }\end{array}$ & $\begin{array}{c}\text { Competition } \\
\text { Mean } \\
\text { (SD) }\end{array}$ & $\begin{array}{c}\text { Control } \\
\text { Mean } \\
\text { (SD) }\end{array}$ & $\begin{array}{c}\text { Competition } \\
\text { Mean } \\
\text { (SD) }\end{array}$ \\
\hline \multirow[t]{2}{*}{ External } & .97 & .84 & 1.00 & 1.03 & .89 & .83 \\
\hline & (1.10) & $(0.60)$ & $(1.22)$ & $(.80)$ & $(.98)$ & $(.64)$ \\
\hline \multirow[t]{2}{*}{ Introjected } & 1.33 & 1.52 & 1.78 & 2.02 & 1.45 & 1.17 \\
\hline & (1.33) & $(.88)$ & (1.42) & (1.08) & $(1.02)$ & $(.97)$ \\
\hline \multirow[t]{2}{*}{ Identified } & 2.30 & 2.73 & 2.65 & 3.03 & 2.40 & 2.58 \\
\hline & $(.96)$ & $(.71)$ & (1.04) & (.63) & $(1.04)$ & $(.76)$ \\
\hline \multirow[t]{2}{*}{ Intrinsic } & 1.77 & 2.52 & 2.12 & 2.98 & 2.23 & 2.64 \\
\hline & (1.14) & $(.78)$ & $(1.28)$ & $(.77)$ & $(1.26)$ & $(.82)$ \\
\hline \multirow[t]{2}{*}{ Amotivation } & .50 & .72 & .62 & .39 & .67 & .64 \\
\hline & $(.79)$ & $(.76)$ & (1.12) & $(.47)$ & $(1.06)$ & $(.87)$ \\
\hline
\end{tabular}

From descriptive statistics shown above, there were found that the participants within both groups increased external, introjected, identified, and intrinsic motivation scores from pre- to post-manipulation period. However, the scores of amotivation only decreased in competition group, while in control group showed an increase. Furthermore, the mean results displayed in the Table 1 also indicated that control group decreased the external motivation scores, but increased the scores in introjected, identified, intrinsic, and amotivation between pre-manipulation and session 3. Interestingly, the competition group only increased the intrinsic motivation scores, but decreased the scores in the rest types of motivation during the same period. The graphs below show the mean differences of motivation types from session 2 (pre- to post-manipulation) and session 3 between two groups. 


\section{Fatmawati et al.}

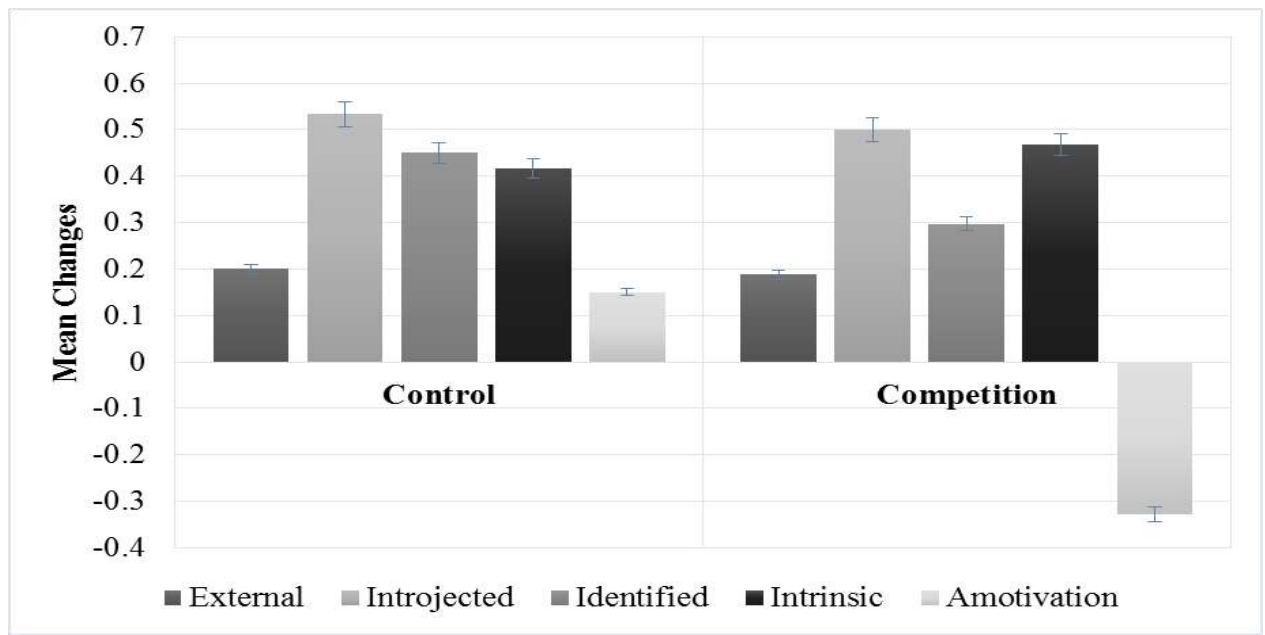

Figure 1. The mean changes of motivation types' scores from pre- to post-manipulation period between control and competition group

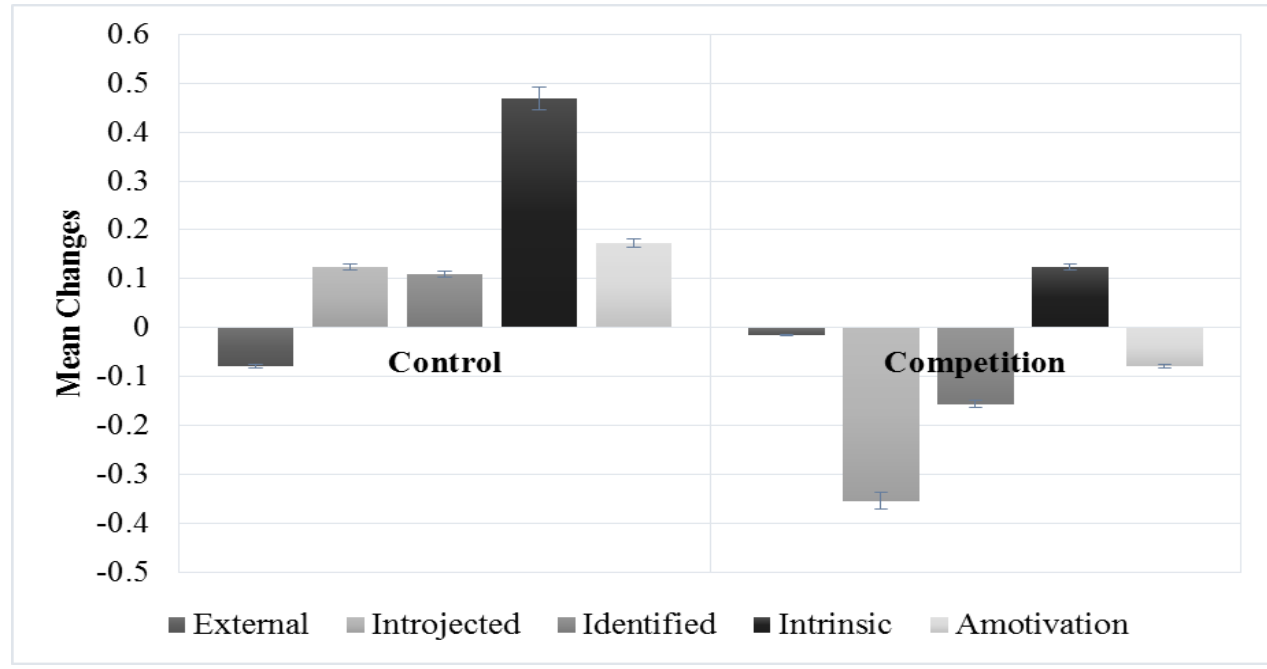

Figure 2. The mean changes of motivation types' scores from pre-manipulation to session 3 between control and competition group

Based on those results, therefore an ANCOVA was then performed in order to identify a statistically significant difference between control and competition group on the motivation types' scores during postmanipulation and session 3 after controlling for pre-manipulation scores. The results revealed that the significant effect of the condition on the 
motivation types' scores only found in amotivation scores during postmanipulation period, $F(1,28)=4.67, p=.04$, while the effect of the condition on the rest of motivation types' scores was not significant in both post-manipulation and session 3 period. From the table of mean presented above, it could be realized that the effect of the condition on the amotivation scores during post-manipulation period was due to participants in the competition group decreased their amotivation scores significantly relative to control group. However, the effect of the condition on amotivation scores during session 3 was found to be not significant.

As the amotivation scores between two groups showed a significant difference during post-manipulation period, so a Nonparametric Bootstrapping analysis was conducted to identify the mediational model of amotivation as a mediator of the relationship between competition intervention and pedometer steps. The results are summarized in the schematic model below.

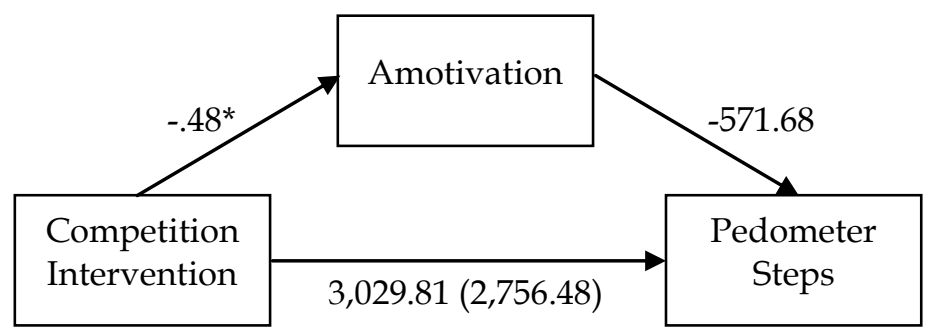

Note: $p<.05$

Figure 3. Standardized beta coefficients for the relationship between competition intervention and pedometer steps as mediated by amotivation

Results based on 2,000 bootstrapped samples indicated that the total effect (TE) of competition intervention on pedometer steps was marginally significant $(\mathrm{TE}=3,029.81, \mathrm{SE}=1,641.97, p=.08$ ), while the direct effect (DE) was not significant ( $\mathrm{DE}=2,756.48, \mathrm{SE}=1,822.42, p=.14$ ). In addition, a non-significant result also found in the indirect effect (IE) of amotivation (IE lower 95\% CI $=-1,308.73$, upper 95\% CI $=1,855.39, p=$ .73), therefore, the effect of the competition intervention on pedometer steps was not mediated by amotivation. 


\section{Discussions}

The finding regarding an increase found in amotivation scores during session 3 is contrary with several literatures that propose the competition may decrease the level of the amotivation across the time periods (Teixeira et al., 2012; Cheon \& Reeve, 2015; Jackson-Kersey \& Spray, 2015). However, it could be an explanation that before the intervention was given, most of the participants did not know about the specific purpose of achieving at least 10,000 steps each day, hence, after receiving the intervention instruction which contained the health benefits from walking 10,000 steps every day, they became aware and found a connection between the behaviour and its outcome. Therefore, the amotivation scores decreased in post-manipulation period.

Furthermore, as research findings did not support the hypotheses $1 \mathrm{a}, 1 \mathrm{~b}, 1 \mathrm{c}$, and $1 \mathrm{~d}$; these are also contradictory with the previous studies that suggest the competition might significantly increase the intrinsic, identified, introjected, and external motivation. It may be the current study was unsuccessful to identify a significant effect due to the data collection process was took place from April to August, where most of the participants faced the deadline with final examination and dissertation. Therefore, these situations might decrease their motivation as they found it impossible to compete to achieve 10,000 steps during the same time. This is in line with the previous literatures which mention that perception of chances for success is one of the fundamental factors that can determine the effectiveness of competition to increase motivation (van de Pol \& Kavussanu, 2012).

Moreover, Charness and Gneezy (2009) mentioned that sometimes the competition may also destroy the motivation itself. This might be due to the personality traits of the people, when they consider themselves as competitive, competition is likely to enhance their motivation, and vice versa (Adie, Duda, \& Ntoumanis, 2010; Findlay \& Bowker, 2009). Besides, some studies also demonstrate that the competition is effective for those who have high achievement and low affiliation needs, as well as low 
anxiety levels (Binboga, Guven, Çatıkkaş, Bayazıt, \& Tok, 2012). Thus, as this current report does not explore the moderator effects, it might be possible that certain participants who had lower scores in competitiveness, conscientiousness, and social comparison found this intervention was not useful, which then did not affect their motivation.

Lastly, as motivation was not found to mediate the changes in steps across the condition; this is inconsistent with the majority literatures which indicated that motivation is a good predictor for physical activity (Mata et al., 2009; Chatzisarantis \& Hagger, 2009; Brunet \& Sabiston, 2011). For instance, the systematic review conducted by Teixeira et al. (2012) found that autonomous types of motivation (intrinsic, introjected, identified, and external) show the positive relationship with exercise behaviour, while amotivation demonstrates a negative relationship. These mean that the higher the scores in those autonomous motivations and the lower the scores in amotivation, the higher the likelihood of exercise participation.

However, according to Ingledew and Markland (2007), there are some behaviours that are not essentially pleasurable for a majority of people, and walking can be one of those behaviours. Furthermore, as mentioned by Silva et al (2010), even introjected motivation shows an increase over the time, it is not necessarily meant that this variable mediate the change in exercise behaviour. Besides, as identified motivation embodies the values which attached to a behaviour (Ryan \& Deci, 2002), so it might be possible that some participants did not value the benefits of 10,000 steps per day for their health. Thus, it is reasonable if motivation failed to be a mediator for increasing steps.

\section{E. Conclusions}

The results from this present study was not defense the preliminary evidence regarding the mediating effect of motivation types on the effectiveness of competition intervention. This might be happened due to several reasons, such as lack of understanding about the benefits of 
walking 10,000 steps/ day, considered walking as unimportant activity, and also the absence of several other potential moderator variables that may affect the competition itself. As mentioned in the discussion session, it might be possible that certain participants who had lower scores in competitiveness, conscientiousness, and social comparison found this intervention was not useful, which then did not affect their motivation.

\section{F. Recommendation}

As no health measures were included before and after the intervention was given, thus the specific health benefits among the participants are unidentified. As the systematic review proposed by Tschentscher, Niederseer, and Niebauer (2013) noticed some benefit effects of walking on heart rate, oxygen consumption, and blood pressure, so incorporating any health measurements in the future study might be useful to investigate the direct impacts of the intervention on health.

\section{Bibliography}

Adie, J. W., Duda, J. L., \& Ntoumanis, N. (2010). Achievement goals, competition appraisals, and the well-and ill-being of elite youth soccer players over two competitive seasons. Journal of Sport and Exercise Psychology, 32, 555-579. Retrieved from http://eprints.bham.ac.uk/321/

Binboga, E., Guven, S., Çatıkkaş, F., Bayazıt, O., \& Tok, S. (2012). Psychophysiological responses to competition and the big five personality traits. Journal of Human Kinetics, 33, 187-194. doi: 10.2478/v10078-012-0057-x

Brunet, J., \& Sabiston, C. M. (2011). Exploring motivation for physical activity across the adult lifespan. Psychology of Sport and Exercise, 12(2), 99-105. doi: 10.1016/j.psychsport.2010.09.006

Charness, G., \& Gneezy, U. (2009). Incentives to exercise. Econometrica, 77(3), 909-931. doi: 10.3982/ECTA7416

Chatzisarantis, N. L., \& Hagger, M. S. (2009). Effects of an intervention based on self-determination theory on self-reported leisure-time 
physical activity participation. Psychology and Health, 24(1), 29-48. doi: 0.1080/08870440701809533

Chemolli, E., \& Gagné, M. (2014). Evidence against the continuum structure underlying motivation measures derived from selfdetermination theory. Psychological Assessment, 26(2), 575-585. doi: $10.1037 / \mathrm{a} 0036212$

Cheon, S. H., \& Reeve, J. (2015). A classroom-based intervention to help teachers decrease students' amotivation. Contemporary Educational Psychology, 40, 99-111. doi: 10.1016/j.cedpsych.2014.06.004

Deci, E. L., \& Ryan, R. M. (2012). Motivation, personality, and development within embedded social contexts: An overview of self-determination theory. In R. M. Ryan (Ed.). The Oxford handbook of human motivation. Retrieved from https:/ / books.google.co.uk/books?hl=en\&lr=\&id=oqsezTrzKZEC\&oi=f nd\&pg=PP2\&dq=The+Oxford+handbook+of+human+motivation\&ots= $\mathrm{mWQBxG \_ lw \& sig=jslafaGpwaMxA5alGHCJ5mEPjy4 \# v=onepage \& q=}$ The $\% 200 x$ ford $\%$ 20handbook\%20of\%20human $\%$ 20motivation\&f=false

Findlay, L. C., \& Bowker, A. (2009). The link between competitive sport participation and self-concept in early adolescence: A consideration of gender and sport orientation. Journal of Youth and Adolescence, 38(1), 29-40. doi: 10.1007/s10964-007-9244-9

Fortier, M. S., Duda, J. L., Guerin, E., \& Teixeira, P. J. (2012). Promoting physical activity: Development and testing of self-determination theory-based interventions. International Journal of Behavioural Nutrition and Physical Activity, 9(1), 20-33. Retrieved from http://www.ijbnpa.org/content/9/1/20

Foster, D., Linehan, C., Kirman, B., Lawson, S., \& James, G. (2010, October $\left.6^{\text {th }} 8^{\text {th }}\right)$. Motivating physical activity at work: Using persuasive social media for competitive step counting. Paper presented at 14th MindTrek Conference. $\quad$ Retrieved from http://core.ac.uk/download/pdf/53330.pdf

Ingledew, D. K., \& Markland, D. (2008). The role of motives in exercise participationt. Psychology and Health,23(7), 807-828. doi: 10.1080/08870440701405704

Jackson-Kersey, R., \& Spray, C. (2015). The effect of perceived psychological need support on amotivation in physical education. 
Fatmawati et al.

European Physical Education Review, 1-14. doi: 10.1177/1356336X15591341

Kaylene, P., \& Rosone, T. L. (2016). Multicultural Perspective on the Motivation of Students in Teaching Physical Education. Jurnal Ilmiah Peuradeun, 4(1), 115-126.

Lim, B. C., \& Wang, C. J. (2009). Perceived autonomy support, behavioural regulations in physical education and physical activity intention. Psychology of Sport and Exercise, 10(1), 52-60. doi: 10.1016/j.psychsport.2008.06.003

Malhotra, D. (2010). The desire to win: The effects of competitive arousal on motivation and behaviour. Organizational Behaviour and Human Decision Processes, 111(2), 139-146. doi: 10.1016/j.obhdp.2009.11.005

Markland, D., \& Tobin, V. (2004). A modification to the behavioural regulation in exercise questionnaire to include an assessment of amotivation. Journal of Sport and Exercise Psychology, 26(2), 191-196. Retrieved from http://journals.humankinetics.com/AcuCustom/Sitename/Documents /DocumentItem/3026.pdf

Milyavskaya, M., \& Koestner, R. (2011). Psychological needs, motivation, and well-being: A test of self-determination theory across multiple domains. Personality and Individual Differences, 50(3), 387-391. doi: 10.1016/j.paid.2010.10.029

Mullan, E., Markland, D., \& Ingledew, D. K. (1997). A graded conceptualization of self-determination in the regulation of exercise behaviour: Development of a measure using confirmatory factor analysis. Personality and Individual Differences, 23(5), 745-752. doi: 10.1016/S0191-8869(97)00107-4

Ng, J. Y., Ntoumanis, N., Thøgersen-Ntoumani, C., Deci, E. L., Ryan, R. M., Duda, J. L., \& Williams, G. C. (2012). Self-determination theory applied to health contexts a meta-analysis. Perspectives on Psychological Science, 7(4), 325-340. doi: 10.1177/1745691612447309

Peng, W., Crouse, J. C., \& Lin, J. H. (2012). Using active video games for physical activity promotion: A systematic review of the current state of research. Health Education and Behaviour, 1-22. doi: $10.1177 / 1090198112444956$

Rodgers, W. M., Hall, C. R., Duncan, L. R., Pearson, E., \& Milne, M. I. (2010). Becoming a regular exerciser: Examining change in 
behavioural regulations among exercise initiates. Psychology of Sport and Exercise, 11(5), 378-386. doi: 10.1016/j.psychsport.2010.04.007

Rouse, P. C., Ntoumanis, N., Duda, J. L., Jolly, K., \& Williams, G. C. (2011). In the beginning: Role of autonomy support on the motivation, mental health and intentions of participants entering an exercise referral scheme. Psychology and Health, 26(6), 729-749. doi: 10.1080/08870446.2010.492454

Ryan R. M., Williams G. C., Patrick H., \& Deci E. L. (2009). Selfdetermination theory and physical activity: The dynamics of motivation in development and wellness. Hellenic Journal of Psychology, 6, 107-124. Retrieved from http://www.ijbnpa.org/content/9/1/78

Ryan, R. M., \& Deci E. L. (2002). An overview of self-determination theory: An organismic-dialectal perspective. In E. L. Deci \& R. M. Ryan (Eds.), Handbook of self-determination research. Retrieved from https:/ / books.google.co.uk/books?hl=en\&lr=\&id=DcAe2b7LRgC\&oi=fnd\&pg=PP11\&dq=Handbook + of + self determination+research\&ots $=$ dqyL2I04Yl\&sig $=4 \mathrm{kB}-$ DXQwekPUUeDyHDYdxBoqwoc\# $\mathrm{v}=$ onepage\& $\mathrm{q}=$ Handbook $\% 20 \mathrm{o}$ $\mathrm{f} \%$ 20self-determination \%20research\&f=false

Saifullah. (2015). The Internalization of Democratic Values into Education and Their Relevance to Islamic Education Development (Synthetic, Analytic, and Eclectic Implementation of John Dewey's Thoughts). Advanced Science Letters, 21 (7), 2301- 2304, DOI: $10.1166 /$ asl.2015.6257

Saifullah. (2017). Learning by Conscience as a New Paradigm in Education. Advanced Science Letters, 23, (2), 853-856, DOI: 10.1166/asl.2017.7447

Salami, S. (2015). Implementing Neuro Linguistic Programming (NLP) in Changing Students' Behavior: Research Done at Islamic Universities in Aceh. Jurnal Ilmiah Peuradeun, 3(2), 235-256.

Silva M. N., Markland D. M., Vieira P. N., Coutinho S. R., Carraça E. V., Palmeira A. L., Minderico C. S., Matos M. G., Sardinha, L. B., \& Teixeira, P. J. (2010). Helping overweight women become more active: Need support and motivational regulations for different 
forms of physical activity. Psychology of Sports and Exercise, 11, 591601. doi: 10.1016/j.psychsport.2010.06.011

Tabrani. ZA \& Masbur, M. (2016). Islamic Perspectives on the Existence of Soul and Its Influence in Human Learning (A Philosophical Analysis of the Classical and Modern Learning Theories). Jurnal Edukasi: Jurnal Bimbingan Konseling, 1(2), 99-112.

Teixeira, P. J., Carraça, E. V., Markland, D., Silva, M. N., \& Ryan, R. M. (2012). Exercise, physical activity, and self-determination theory: A systematic review. International Journal of Behavioural Nutrition and Physical Activity, 9(1), 78-107. Retrieved from http://www.ijbnpa.org/content/9/1/78

Tschentscher, M., Niederseer, D., \& Niebauer, J. (2013). Health benefits of Nordic walking: A systematic review. American Journal of Preventive Medicine, 44(1), 76-84. doi: 10.1016/j.amepre.2012.09.043

Van de Pol, P. K., \& Kavussanu, M. (2012). Achievement motivation across training and competition in individual and team sports. Sport, Exercise, and Performance Psychology, 1(2), 91-105. doi: $10.1037 / \mathrm{a} 0025967$

Walidin, W., Idris, S \& Tabrani. ZA. (2015). Metodologi Penelitian Kualitatif dan Grounded Theory. Banda Aceh: FTK Ar-Raniry Press

Yusoff, M. Z. M., \& Hamzah, A. (2015). Direction of Moral Education Teacher To Enrich Character Education. Jurnal Ilmiah Peuradeun, 3(1), 119-132. 
p-ISSN: 2338-8617

Vol. 6, No. 1, January 2018 e-ISSN: 2443-2067 